\title{
A carreira do professor da rede pública de Chicago ${ }^{12}$
}

Howard S. Becker*

*(Universidade de Washington, Seattle, Washington, EUA)
Resumo: As carreiras dos professores de Chicago exibem movimentações "horizontais" entre cargos em um mesmo nível da hierarquia escolar, em termos de configuração dos problemas profissionais básicos apresentados por cada cargo, mais do que movimentações verticais entre vários desses níveis. Um grande padrão de carreira consiste em mudar-se da escola de classe baixa, onde as carreiras geralmente começam; outro padrão consiste em adaptarse, ao longo de um período de anos, aos problemas de tais escolas. Uma vez estabelecido em uma escola, o professor pode ser perturbado por mudanças relacionadas à estrutura da vizinhança ou ao pessoal administrativo com quem ele lida.

Palavras-chave: Carreira docente. Movimentação docente. Desigualdades socioespaciais. Relações étnico-raciais.

Artigo apresentado ao Instituto da Sociedade para Pesquisas Sociais, em Chicago, em 8 de junho de 1951. 0 material aqui apresentado é parte de um estudo maior relatado em "Role and Career Problems of Chicago Public School Teacher" (Tese de doutorado não publicada, Departamento de Sociologia, Universidade de Chicago), 1951.

2 Originalmente publicado no periódico American Journal of Sociology (v. 57, n. 5, p. 470-477, mar. 1952), com o título "The career of the Chicago Public Schoolteacher". Traduzido e publicado com autorização. Tradução de Fernando Effori. 
Howard S. Becker é um sociólogo estadunidense. Foi professor nas universidades de Chicago, Northwestern e de Washington e passou um período como pesquisador do Museu Nacional, no Rio de Janeiro.

Assim como outros grandes sociólogos, transitou em sua carreira em temáticas diversas, como a sociologia da arte, da delinquência e metodologia de pesquisa. Sua produção é notável, com mais de 13 livros publicados, além de muitos artigos. Atualmente com 90 anos, mora em San Francisco (Califórnia) e continua ativo em sua produção. Mantém atualizado um site com sua obra e informações pessoais: http://www.howardsbecker.com/

Seu texto "A carreira do professor da rede pública de Chicago" teve grande influência nas pesquisas desenvolvidas pelo Cenpec, especialmente as sobre desigualdades socioespaciais e interdependência entre escolas. Com sua escrita clara e precisa, traz elementos importantes para compreender como se dá a movimentação docente entre escolas. É impressionante como continua atual.

O conceito de carreira tem se mostrado de grande utilidade para compreendere analisara dinâmica dasorganizações do mundo dotrabalho eas movimentações e destinos dos indivíduos dentro delas. $O$ termo refere-se, parafraseando Hall (1948), às séries padronizadas de adaptações realizadas pelos indivíduos à "rede de instituições, organizações formais, e relacionamentos informais" nas quais a atividade da profissão é realizada. Esta série de adaptações é geralmente considerada em termos de uma movimentação para cima ou para baixo, entre cargos diferenciados por seu nível em alguma hierarquia formal ou informal de prestígio, influência e renda. A literatura do campo tem se dedicado, basicamente, a uma análise dos tipos, estágios e contingências das carreiras assim concebidas, em várias profissões (ver HUGHES, 1937; HALL, 1948, 1949; DALTON, 1951). Podemos nos referir a tal mobilidade em uma hierarquia de cargos de diferentes níveis, se uma metáfora espacial nos for permitida, como sendo o aspecto vertical da carreira.

Ao voltarmos nossa atenção para esse aspecto das movimentações de carreira, podemos tender a desconsiderar o que, em contraste, poderia ser chamado de aspecto horizontal da carreira: movimentações entre os cargos disponíveis em um mesmo nível da hierarquia. Não é preciso pressupor que cargos profissionais com algumas características em comum, devido ao seu nível semelhante numa estrutura formal, sejam idênticos em todos os sentidos. Eles podem, inclusive, ser muito diferentes quanto à configuração 
dos problemas profissionais básicos que apresentam. Isto é, todos os cargos no mesmo nível de uma hierarquia de trabalho, embora teoricamente idênticos, podem não ser lugares igualmente fáceis ou gratificantes para se trabalhar. Diante desse fato, as pessoas tendem a se movimentar de formas padronizadas entre os possíveis cargos, buscando aquela situação que thes proporcione o cenário mais desejável para encarar e lidar com os problemas básicos de seu trabalho. Em algumas profissões, mais do que em outras, e para alguns indivíduos, mais do que para outros, esse tipo de movimentação de carreira assume maior importância do que a variedade vertical, às vezes a tal ponto que toda a trajetória da carreira consiste em movimentações inteiramente no mesmo nível de uma hierarquia de trabalho.

Os professores das escolas públicas de Chicago são um grupo cujas carreiras geralmente tendem para este último extremo. Embora seja possível a qualquer professor com a formação adequada prestar o exame para a posição de diretor e tentar ascender na hierarquia administrativa do sistema escolar, poucos fazem o esforço. A maioria vê suas carreiras puramente no ensino, em termos de movimentação entre as várias escolas da rede de Chicago ${ }^{3}$. Mesmo os que tentam o tipo de mobilidade vertical já esperam passar alguns anos na categoria de professor e, durante esse tempo, veem esse segmento de suas carreiras praticamente da mesma forma. Este artigo analisará a natureza desse tipo de movimentação horizontal de carreira entre os professores e descreverá os tipos de carreira encontrados neste grupo. Evidentemente, estes não são os únicos padrões que podemos esperar encontrar nesse plano horizontal de movimentação de carreira. Cabe a outros estudos, em outras profissões, diferenciar outras variedades de carreira e as condições nas quais cada tipo ocorre.

A análise se baseia em entrevistas com 60 professores da rede de Chicago. As entrevistas foram, em grande medida, do tipo não estruturado, e variaram em certo grau com cada entrevistado, de acordo com a dificuldade encontrada para superar a desconfiança e o medo dos professores em falar com pessoas de fora de seu meio. Apesar dessa resistência, baseada na ansiedade ligada às consequências de ser entrevistado, um material de validade suficiente foi garantido para a análise aqui realizada por meio da insistência para que todas as afirmações gerais sobre atitude fossem apoiadas por descrições concretas de experiências reais. Esse procedimento, é o que se percebeu,

\footnotetext{
A rede de Chicago possui um plano salarial elevado o bastante, e garantias de seguridade suficientes, para ser um sistema seguro, no qual uma pessoa pode fazer toda a sua carreira, diferindo, assim, de redes de ensino menores, nas quais o professor não espera passar toda a sua vida profissional.
} 
obrigou os entrevistados a revelar mais do que, de outra forma, poderiam revelar, ao solicitarmos que dessem material factual suficiente para tornar suas afirmações plausíveis e coerentes.

As posições abertas a um determinado professor da rede, num dado momento, parecem, em geral, bastante semelhantes, todas apresentando aproximadamente o mesmo grau correspondente de prestígio, renda e poder. Isso não implica negar a existência de variações de renda criadas em função da antiguidade, ou de diferenças de poder e prestígio informais baseadas no tempo de serviço e no tempo de permanência em determinada escola.

Ainda assim, é verdadeiro que, para um indivíduo com determinada antiguidade e prestes a começar a trabalhar numa escola que lhe é nova, todas as posições da rede de Chicago são iguais com relação a prestígio, influência e renda.

Embora as vagas de ensino disponíveis nas escolas da cidade sejam semelhantes quanto às características formais, elas diferem muito em termos da configuração dos problemas laborais básicos da profissão que apresentam. A carreira do professor consiste em movimentações entre essas várias escolas, em busca da vaga mais satisfatória para se trabalhar, qual seja, aquela em que esses problemas sejam menos graves e mais suscetíveis de solução. Os problemas de trabalho surgem nas relações dos professores com as importantes categorias de pessoas na estrutura da escola: as crianças, os pais, o diretor e outros professores. Os problemas mais difíceis surgem de sua interação com seus alunos. Os professores entendem que a forma e 0 grau desses últimos variam consideravelmente de acordo com a classe social de origem dos alunos.

Sem entrar em qualquer análise detalhada sobre tais problemas ${ }^{4}$, simplesmente resumirei a visão dos professores quanto aos alunos e quanto à relação desses docentes com as várias classes sociais das quais provêm seus estudantes. Os entrevistados geralmente distinguiram três grupos de classe social: (1) uma camada baixa, provavelmente equivalente à classe baixabaixa e partes da classe baixa-alta ${ }^{5}$, incluindo-se aí, para o professor, todos os negros; (2) uma camada alta, provavelmente equivalente à classe média-alta;

4 Artigos posteriores trarão análise e documentação detalhadas sobre as afirmações feitas neste e no próximo parágrafo.

5 As categorias de classes citadas nesta estimativa são as utilizadas por Warner e Lunt (1941). 
e (3) uma camada média, provavelmente equivalente à classe média-baixa e partes da classe baixa-alta. Três grandes tipos de problema foram descritos como oriundos da interação com alunos: (1) o problema de ensinar, produzir nas habilidades e conhecimentos da criança alguma mudança que possa ser atribuída aos esforços do docente; (2) o problema da disciplina, isto é, manter a ordem e o controle sobre as atividades das crianças; e (3) o problema do que se pode chamar de aceitabilidade moral, ou seja, ser capaz de tolerar alguns traços das crianças que sejam considerados imorais ou revoltantes.

0 professor entende que o grupo da classe mais baixa, o das crianças "de regiões socialmente vulneráveis" ${ }^{6 "}$ é difícil de ensinar, incontrolável e violento na esfera da disciplina, e moralmente inaceitável em todos os outros requisitos, do asseio físico às esferas do sexo e da "ambição em subir na vida". As crianças do grupo da classe mais alta, das "melhores vizinhanças", foram consideradas rápidas para aprender e fáceis de ensinar, mas um tanto "mimadas" e difíceis de controlar, além de deficientes nos importantes traços morais de polidez e respeito pelos mais velhos. 0 grupo médio foi considerado esforçado, mas lento para aprender, extremamente fácil de controlar e o mais aceitável em termos morais.

Outros problemas importantes surgem na interação com pais, diretor e colegas, e giram basicamente em torno da questão da autoridade. Os pais dos grupos de status mais elevado, bem como certos tipos de diretor, são extremamente ameaçadores à autoridade que o professor entende ser básica para a manutenção de seu papel; em certas situações, colegas também podem agir de forma a diminuir sua autoridade.

Assim, as posições em nível de docência podem ser muito satisfatórias ou altamente indesejáveis, dependendo da presença ou ausência do tipo "certo" de alunos, pais, diretor e colegas. Onde qualquer uma dessas posições for preenchida pelo tipo “errado" de pessoas, o professor entende que está em situação desfavorável para lidar com os problemas importantes de seu trabalho. Os professores de escolas desse tipo ficam insatisfeitos e desejam mudar para escolas onde as "condições de trabalho" sejam mais satisfatórias.

\footnotetext{
6 O autor utiliza ao longo do artigo a palavra slum, que pode designar distritos ou ruas superpopulosas e habitadas por pessoas muito pobres, bem como locais de moradia inadequados para esse fim. Em português, os termos "favela", "cortiço" ou "regiões socialmente vulneráveis" são próximos do termo em inglês. Dadas as peculiaridades da organização das desigualdades socioespaciais nos EUA e no Brasil, preferiu-se, na tradução, utilizar uma expressão mais genérica como "regiões socialmente vulneráveis". [N. de E.]
} 
As movimentações de carreira para o professor de Chicago são, essencialmente, de uma escola para outra, algumas sendo locais mais satisfatórios para se trabalhar, outras menos. Tais movimentações são realizadas segundo as regras do Conselho de Educação ${ }^{7}$ referentes a transferências, as quais permitem ao professor, após atuar em uma posição por mais de um ano, solicitar transferência para uma dentre até dez outras posições. A mudança para uma dessas posições torna-se possível quando surge uma vaga para a qual não haja candidato cuja solicitação esteja esperando há mais tempo, e a transferência é efetuada mediante a aprovação pelo diretor da nova escola.

Não se espera que os padrões de carreira encontrados nesta matriz social sejam típicos de todas as movimentações de carreira desse tipo horizontal. É provável que a presença deles limite-se a organizações que, como a rede de ensino de Chicago, sejam impessoais e burocráticas, e nas quais a mobilidade é realizada principalmente por meio da manipulação de procedimentos formais.

II

Os maiores problemas de trabalho encontram-se nas escolas de classe baixa e, consequentemente, a maioria das movimentações na rede resulta da insatisfação com a composição da classe social dessas populações escolares. As movimentações na rede, assim, tendem a ser de saída dos bairros "piores": para os bairros "melhores”, principalmente em termos das características dos alunos. Uma vez que há pouca ou nenhuma solicitação de transferência para escolas “de locais vulneráveis”, a necessidade de professores é preenchida pela designação, para tais escolas, de docentes que estão iniciando suas carreiras na rede de Chicago. Assim, o professor iniciante em geral começa sua carreira no tipo menos desejável de escola9. A partir desse início, descobriuse que se desenvolvem dois tipos principais de carreira.

A primeira variedade de carreira se caracteriza por uma tentativa imediata de mudança para uma escola "melhor”, em um bairro "melhor”. A maioria dos entrevistados que informaram ter tido sua primeira designação para

Nos EUA e em outros países anglofônicos, os boards of education podem ser, como no caso deste artigo, instituições que têm funções próximas às de uma secretaria municipal de educação. [N. de E.]

No original, slums. [N. de E.]

9 Mais documentos sobre este ponto podem ser encontrados em Wagenschein (1951) e em Winget (s.d.). 
uma escola "de bairros pobres"10 já havia realizado ou estava em processo de realizar tal transferência. A atitude é bem descrita nesta citação de um entrevistado:

Quando você é designado pela primeira vez, é quase naturalmente designado para uma dessas escolas mais pobres, porque elas estão naturalmente entre as primeiras a ter vagas, pois as pessoas estão sempre se transferindo delas. Daí você vai e solicita transferência para outras escolas mais perto de sua casa ou em alguma vizinhança melhor. Naturalmente, as vagas não aparecem tão rápido nessas escolas, pois as pessoas, uma vez chegando ali, querem ficar. Acho que todos os professores se esforçam para passar para uma vizinhança melhor.

Realizar uma mudança bem-sucedida desse tipo depende de vários fatores. Primeiro, deve-se ter um conhecimento preciso de quais escolas são "boas" e quais não, para que se possa solicitar com critério. Sem tal conhecimento, o qual se adquire por meio do acesso ao que se diz "à boca pequena”, o que parece ser uma mudança desejável pode se revelar simplesmente uma passagem de mal a pior, como indica a experiência narrada a seguir por um professor:

Quando incluí meu nome para as dez escolas, eu o incluí para uma escola lá em [bairro "bom"]. Eu não sabia nada sobre ela, como era a diretora, nem nada disso, mas ela estava na lista de escolas. Bom, eu ouvi depois, de várias pessoas, que eu tinha realmente cometido um erro. Eles tinham uma diretora ali que era realmente um terror. Ela infernizava a vida de todos...

Mas eu estava lhe contando o que aconteceu comigo. Ou quase aconteceu. Depois que eu soube sobre essa diretora, me disseram que ela queria me observar um dia. Bom, eu fiquei muito assustado. Se ela tivesse me aceitado, teria sido um grande azar, eu teria de ficar lá por um ano. Mas ela nunca apareceu na minha sala... Mas, o que quer que tenha sido, o fato é que fiquei feliz por não ter de ir para lá. Isso só mostra que você tem de ter cuidado com a escola que escolhe.

Em segundo lugar, para realizar uma mudança bem-sucedida, o professor não deve ser de um tipo étnico ou ter uma reputação pessoal que leve o diretor a usar seu poder de rejeição informal. Embora um candidato possa ser rejeitado por meio de procedimentos burocráticos, o diretor acha mais fácil e menos embaraçoso obter o mesmo resultado por este método, descrito por um professor negro:

Ele só precisa dizer: "Acho que você não vai ser muito feliz na nossa escola". Você já entende logo. Porque se o diretor decidir que você vai ser infeliz, você vai ser, não se preocupe. Não há dúvida quanto a isso. Ele pode arranjar para você ter todos os problemas de disciplina da série que você leciona bem na sua sala. É o bastante para estragar tudo. Então, realmente não vale a pena ir, se não querem você. Você pode lutar contra, se quiser, mas eu estou velho demais para esse tipo de coisa agora.

10 No original, slums. [N. de E.] 
Isso tem o efeito de destruir as qualidades atraentes da escola para a qual a transferência era desejada, e encaminhar a escolha em uma nova direção.

Finalmente, deve-se ser paciente o bastante para esperar que a transferência para a escola "certa" seja consumada, e não sucumbir à tentação de se transferir para uma escola menos desejável, mas mais acessível:

Quando fui designada para [escola de negros], por exemplo, assinei dez listas nesta vizinhança. Eu moro aqui há 25 anos e espero ficar aqui, então me candidatei a essas escolas e resolvi que esperaria dez anos, se necessário, até que encontrei uma vaga na vizinhança.

A maioria dos professores tem carreiras desse tipo, nas quais um período inicial em uma escola indesejável "de regiões socialmente vulneráveis" é seguido pela manipulação do sistema de transferência, de modo a obter uma designação para um tipo mais desejável de escola.

Treze dos entrevistados, entretanto, tinham carreiras de um tipo diferente, caracterizado por uma adaptação permanente à situação da escola “de regiões socialmente vulneráveis”. Essas carreiras foram fruto de um processo de adaptação à situação específica de trabalho, o qual, embora opere em todas as escolas, é visto mais claramente onde ele tem um efeito radical no desenvolvimento futuro da carreira, atando o professor a uma escola que, de outra forma, seria considerada indesejável. O processo começa com o professor, por qualquer uma dentre várias razões possíveis, permanecendo na escola indesejada por um dado número de anos. Durante esse período, mudanças ocorrem no professor e no caráter de suas relações com os outros membros da estrutura social da escola, transformando essa escola insatisfatória em um lugar mais fácil para se trabalhar, e modificando a visão do professor sobre os benefícios a se obter com a transferência para outro lugar. Havendo as circunstâncias apropriadas, toda a carreira de uma pessoa pode transcorrer dentro de uma dessas escolas.

Durante esse período inicial, mudanças ocorrem nas habilidades e atitudes do professor, atenuando o desconforto de ensinar em uma escola "de regiões socialmente vulneráveis". Primeiro, ele aprende novas técnicas de ensino e disciplina que the possibilitam lidar adequadamente com as crianças dessas regiões, embora não sejam adequadas para uso com grupos de outras classes sociais: 
Tecnicamente, não se deve encostar a mão em uma criança. Bem, tecnicamente, os professores não encostam. Mas há várias formas de manipular uma criança de modo a não aparentar - e aí, é a palavra do professor contra a da criança, então, a criança não tem chance. Tal como a cara Sra. [nome]. Quando se zanga com um aluno, ela o leva para o corredor, e faz com que ele encoste na parede. Então, ela conhece um modo de dar um afago sob o queixo, porém com força, batendo a parte de trás da cabeça do aluno contra a parede. Isso não deixa marcas. Mas quando o aluno retorna à sala, mal consegue entender o que se passa, de tão atordoado.
Além disso, o professor aprende a rever suas expectativas com relação à quantidade de matéria que pode ensinar, e aprende a se satisfazer com realizações menores; um diretor de uma escola "de pobres" descreveu assim uma adaptação por parte de seus professores:

Nossos professores ficam bem satisfeitos se as crianças conseguem ler e fazer operações numéricas simples quando saem daqui... Eles só tentam passar essas coisas básicas. Para que, se as crianças forem para o ensino médio, possam demonstrar que sabem algo $e$ conseguir se virar.
Assim, o professor adquire uma rotina de trabalho costumeira, favorável e previsível, a tal ponto que qualquer mudança requereria uma transformação drástica em hábitos arraigados.

Finalmente, ele descobre sozinho explicações para ações das crianças que antes achava revoltantes e imorais, e tais explicações lhe permitem "entender" o comportamento das crianças como humano, e não como atividade de lunáticos ou animais:

Eu finalmente recebi minha designação permanente na [nome da escola]. É uma grande escola "de cor". Sinceramente, eu não estava pronto para nada parecido. Pensei que fosse enlouquecer naqueles primeiros meses que passei ali. Eu não estava acostumado àquele tipo de confusão e barulho. A sala nunca ficava totalmente em silêncio. Havia sempre um som de fundo, um murmúrio de conversas, cochichos e empurrões... Pensei que não seria capaz de aguentar. Mas, quando passei a entendê-los, aí pareceu diferente. Quando consegui entender as condições em que eles eram criados, o tipo de vida familiar e o lar de onde vinham, me pareceu mais natural que eles agissem daquele jeito. E eu realmente me acostumei, depois de algum tempo.

Ao mesmo tempo que essas mudanças ocorrem nas perspectivas do professor, ele também vai gradualmente se integrando à rede de relações sociais que constituem a escola, de forma tal que os problemas associados à escola “de regiões socialmente vulneráveis" são atenuados. Em primeiro lugar, o professor, durante o longo período na escola, acaba sendo aceito pelos outros professores como um igual confiável, e adquire posições de influência 
e prestígio na estrutura informal dos colegas. Essas mudanças facilitam a ele manter sua posição de autoridade diante das crianças e do diretor. Qualquer mudança de escola significaria uma perda de tal posição e suas vantagens, e a necessidade de conquistar a aceitação dos colegas em outro local.

Em segundo lugar, o problema da disciplina é atenuado quando a reputação de firmeza do professor começa a fazer o trabalho de manutenção da ordem por ele:

Eu não tenho problema com as crianças. Uma vez estabelecida a reputação, elas sabem o que esperar, elas o respeitam e você não tem problemas. Claro, isso é diferente para um professor novo, mas quando você já se estabeleceu, não há problema nenhum.

Finalmente, os problemas de manter a autoridade em relação aos pais diminuem à medida que a pessoa se torna uma "peça" da comunidade e constrói relacionamentos estáveis e duradouros com suas famílias: "Mas, como eu digo, quando você já está nessa vizinhança há tanto tempo quanto eu, todo mundo o conhece, e você já esteve em metade das casas deles, então nunca há problema algum”.

A escola “de regiões socialmente vulneráveis” é, assim, se não ideal, ao menos tolerável e previsível para o professor que se adaptou a ela. Ele já recebeu o pior que a situação tem a oferecer, e aprendeu a conviver com isso. Ele está atado à escola pela rotina que desenvolveu para atender seus requisitos e pelas relações que construiu com os outros na organização escolar ${ }^{11}$. Essas mesmas adaptações fazem com que ele, ao mesmo tempo, tema mudarse para qualquer nova escola, o que requereria uma reconstrução desses relacionamentos e uma completa reorganização de suas técnicas e rotina de trabalho. A mudança para uma escola em um bairro "melhor” é particularmente temida, por mais desejável que pareça em termos abstratos, pois o professor acostumado à relativa liberdade da escola "de cortiço" não tem certeza se as vantagens a se obter em tal mudança não seriam contrabalançadas pela restrição imposta por pais que "interferem" e crianças “mimadas”, e pelas dificuldades a enfrentar para se integrar em uma nova estrutura escolar. Essa adaptação completa a uma situação específica de trabalho age, assim, como um freio à continuação da mobilidade no sistema.

11 Para uma análise posterior do modo como professores se adaptam às escolas vulneráveis, ver Van Zanten (2001), que descreve tipos de docentes e suas formas de adaptação. 
Qualquer um desses padrões de carreira termina por resultar na conquista pelo professor de uma posição na qual ele se encontra mais ou menos estabelecido em um ambiente de trabalho que considera previsível e satisfatório. Uma vez que isso ocorra, sua posição e carreira ficam sujeitas a perigos ocasionados por acontecimentos ecológicos ${ }^{12}$ e administrativos que provoquem mudanças radicais com relação aos ocupantes de posições importantes na estrutura escolar.

Mudanças na ecologia de uma vizinhança produzem transformações no grupo de classe social do qual advêm os alunos e pais de determinada escola. Isso, por sua vez, modifica a natureza e a intensidade dos problemas de trabalho do professor e perturba o docente que estava acostumado a trabalhar com um grupo de status mais elevado do que aquele que ele acaba por herdar. 0 efeito total é a destruição daquilo que um dia foi um local satisfatório para se trabalhar, uma posição em relação à qual não se pretendia mudança alguma:

Estou nessa escola há cerca de 20 anos. Era uma escola adorável quando cheguei... Claro, a vizinhança mudou um bocado durante esse tempo que passei ali. Não é mais o que era antes.

A vizinhança costumava ser 90\%, 95\% judaica. Agora, acho que não há mais do que 40\% de judeus. $O$ restante são gregos, italianos, alguns irlandeses, está bem misturado agora. $E$ as crianças não são mais tão boazinhas como antes.

Processos ecológicos e geográficos podem, igualmente, provocar uma mudança na estrutura etária de uma população, causando uma redução no número de professores necessários em determinada escola e a consequente perda da posição nessa escola por parte de quem foi incorporado por último ao quadro de funcionários. O efeito da invasão de vizinhança pode ser o redirecionamento da carreira no sentido de uma adaptação ao novo grupo, enquanto a mudança na estrutura etária local pode fazer a carreira retornar à fase anterior, na qual se buscava uma transferência para uma escola “melhor”.

Uma posição satisfatória também pode ser alterada para pior devido a uma mudança de diretores, por meio de transferência ou aposentadoria. A saída de um diretor pode produzir mudanças de tal dimensão na atmosfera escolar a ponto de obrigar professores a se transferir para outro lugar. Em locais onde o diretor era uma força importante na sustentação da autoridade dos professores

12 O sociólogo refere-se a mudanças sociodemográficas no entorno da escola e que a impactam. [N. de E.] 
em face de ataques por parte de crianças e pais, uma mudança pode produzir um aumento desastroso dos problemas de disciplina e interferência parental:

Fico tentado a colocar a maior parte da culpa em nosso novo diretor... [O antigo diretor] mantinha uma ordem excelente. Agora, as crianças não parecem mais sentir o mesmo em relação a esse sujeito. Elas não têm medo dele, não o respeitam. E a disciplina na escola tem sofrido tremendamente. A escola toda está menos ordeira agora.

Esse problema é considerado mais sério quando a mudança ocorre em uma escola "de região socialmente vulnerável”, na qual o problema da disciplina vinha sendo mantido sob controle, basicamente, por meio dos esforços de um diretor rígido. As reações a fatos dessa natureza, e seus consequentes reflexos nas carreiras, variam entre as escolas de regiões de classes sociais diferentes. Uma mudança desse tipo em uma escola “vulnerável” geralmente produz um enorme e imediato aumento na rotatividade de professores. Um professor que havia vivenciado uma experiência semelhante estimou que a rotatividade docente subiu de quase nada para $60 \%$ ou mais durante o ano seguinte à mudança. Quando a mudança ocorre em uma escola “melhor”, de classe média-alta, os professores relutam em se mudar e abrir mão de suas posições custosamente obtidas, preferindo arriscar-se com as qualidades do novo diretor. Somente se ele for particularmente insatisfatório, os professores tenderam a se transferir.

Outro temor é de que uma troca de diretores destrua a distribuição existente de privilégios e influência entre os professores, quando o novo diretor deixa de agir nos termos dos entendimentos informais dos professores com relação a tais assuntos. As citações a seguir descrevem dois novos diretores que agiram desse modo:

Ele sabe o que quer, e ele faz. Muitos dos professores mais velhos tentaram explicar algumas coisas, mas ele não quer tomar parte em nada. Não que eles tenham feito isso de forma dominadora ou algo assim, mas ele simplesmente não gosta.

Ele tem um bom coração, é realmente bem-intencionado, mas simplesmente não sabe nada sobre dirigir uma escola. Ele entende tudo errado, ouve pessoas a quem não deveria prestar nenhuma atenção... Algumas pessoas se afirmam e lhe dizem o que fazer, e ele as escuta, quando não deveria.

Essas afirmações são reações de professores mais entrincheirados e "antigos", que dependem muito, para seu poder, da influência que exercem sobre o diretor. Sua insatisfação com um novo diretor raramente afeta suas 
carreiras a ponto de fazer com que se mudem para outra escola. Por outro lado, a chegada de um novo diretor pode ser muito vantajosa e ardentemente desejada por professores mais jovens e menos influentes. O efeito de um fato dessa natureza na carreira de um professor mais jovem é ilustrado nesta citação:

\begin{abstract}
Eu estava pronto para me transferir por causa do antigo diretor. Eu simplesmente não aguentava. Mas quando este novo chegou, e acabou sendo tão bom, fui até a central e tirei meu nome da lista de transferência. Agora eu quero ficar lá. [...] Alguns daqueles professores já estão lá há 30 anos, sabe, e eles se sentem como se realmente fossem os donos do lugar. Querem que tudo seja do jeito deles. Eles sempre tiveram as coisas do jeito deles, e ficaram bem furiosos quando este novo diretor não aceitou todas as suas ideias.
\end{abstract}

Assim, qualquer um desses fatos pode afetar a carreira de qualquer professor de várias formas, dependendo do estágio de desenvolvimento da carreira no momento em que o fato ocorre. 0 efeito de qualquer fato deve ser visto no contexto do tipo de adaptação realizado pelo indivíduo em relação à organização institucional em que ele trabalha.

IV

Este artigo demonstrou a existência, entre professores da rede de ensino de Chicago, do que foi chamado de plano "horizontal" de movimentações e esforços de carreira, e delineou o tipo de padrão de carreira que ocorre, nesse nível, em uma burocracia pública na qual as movimentações são realizadas por meio da manipulação de procedimentos formais. Ele sugere que estudos sobre outras profissões, nas quais uma maior ênfase em movimentações verticais pode obscurecer a presença e os efeitos dessa mobilidade horizontal, bem poderiam dirigir sua atenção para esses fenômenos.

Outras pesquisas também podem explorar em detalhes as relações entre a mobilidade horizontal aqui discutida e a mobilidade vertical mais proeminente em muitas profissões. Estudos em uma série de profissões poderiam nos dar respostas a questões como esta: em que grau, e em quais circunstâncias, uma pessoa abre mão de ações que poderiam lhe proporcionar uma melhor situação de trabalho em um mesmo nível de uma hierarquia profissional, na esperança de receber maiores recompensas por meio da mobilidade vertical? Hall (1948) observa que os médicos que se tornam membros da influente "fraternidade fechada" submetem-se a um "sistema rigoroso de seleção, e um sistema de prolongado aprendizado. Os participantes do sistema devem 
estar preparados para longas demoras antes de ser recompensados por sua lealdade a tal sistema” (p. 334). Percebemos que as recompensas da aceitação final neste importante grupo são atraentes o suficiente para impedir que 0 médico jovem ali inserido como aprendiz tente outras formas de melhorar sua posição. Invertendo o problema, podemos questionar em que grau uma pessoa abre mão de uma possível mobilidade vertical que possa interferir na adaptação bem-sucedida que ela realizou em termos de movimentações horizontais de carreira. Uma sugestão sobre os tipos de relacionamentos e processos aqui encontrados vem da seguinte declaração de um professor de ensino secundário, com relação à mobilidade dentro do sistema escolar:

Esse é um motivo pelo qual muita gente não se interessa em prestar exames para diretor. Supondo que eles passem, e a primeira posição a que são designados é alguma escola como [nome] ou [nome]. E é provável que seja em alguma escola de classe baixa e "de cor”, porque as pessoas estão sempre desesperadas para sair de escolas assim... Essas escolas quase sempre estão vagas, então você tem grandes chances de ser designado para lá, no começo.

Muita gente que eu conheço diz: "Por que eu deixaria uma boa vizinhança como Morgan Park ou South Shore ou Hyde Park para ir para uma escola dessas?" [...]. Eles pensam: "Vou arranjar confusão com algo assim? Gosto mais de onde estou”.

Finalmente, exploramos o fenômeno da adaptação a uma situação específica de trabalho, em termos de mudanças nas perspectivas e relações sociais do indivíduo, e observamos a forma como tais adaptações agiam no sentido de atar o indivíduo à situação específica e de lhe dificultar a consideração de uma mudança para outra situação. Podemos especular sobre a importância e os efeitos de tal processo na mobilidade vertical predominante em muitas profissões. Outro problema de pesquisa pode ser sugerido: que mecanismos sociais atuam, em profissões nas quais não se permite que tal adaptação permaneça imperturbada, para realizar a transição entre situações de trabalho, para romper os laços que vinculam o indivíduo a uma situação e para se efetuar uma nova adaptação em outro lugar? 


\section{The career of the Chicago public schoolteacher}

Abstract: The careers of Chicago teachers exhibit "horizontal" movement among positions at one level of the school-work hierarchy in terms of the configuration of the occupation's basic problems presented by each rather than vertical movement between several such levels. One major career pattern consists in moving from the lower-class school in which careers usually begin; another consists in adjusting, over a period of years, to the problems of such schools. Having settled in a school, the teacher may be upset by changes in neighborhood structure or in the administrative personnel with whom she deals.

Keywords: Teaching career. Teacher movement. Socio-spatial inequalities. Ethnic-racial relations. 


\section{La carrera del profesor de la red pública de Chicago}

Resumen: Las carreras de los profesores de Chicago muestran movimientos "horizontales" entre cargos en un mismo nivel de la jerarquía escolar, en lo que se refiere a la configuración de los problemas profesionales básicos presentados por cada cargo, más que movimientos verticales entre varios de estos niveles. Un gran patrón de carrera consiste en mudarse de la escuela de clase baja, donde las carreras generalmente comienzan; otro patrón consiste en adaptarse, a lo largo de un período de años, a los problemas de tales escuelas. Una vez establecido en una escuela, el profesor puede verse perturbado por cambios relacionados con la estructura de la vecindad o con el personal administrativo con el cual se relaciona.

Palabras clave: Carrera docente. Movimiento docente. Desigualdades socioespaciales. Relaciones etnicorraciales. 


\section{REFERÊNCIAS}

DALTON, Melville. Informal factors in career achievement. American Journal of Sociology, Chicago, v. 56, n. 5, p. 407-415, mar. 1951.

HALL, Oswald. The stages of a medical career. American Journal of Sociology, Chicago, v. 53, n. 5, p. 327-336, mar. 1948.

. Types of medical careers. American Journal of Sociology, Chicago, v. 55, n. 3, p. 243-253, nov. 1949.

HUGHES, Everett C. Institutional office and the person. American Journal of Sociology, Chicago, v. 43, n. 3, p. 404-413, nov. 1937.

VAN ZANTEN, Agnès; GROSPIRON, Marie-France. Les carriers enseignantes dans les établissements difficiles: fuite, adaptation et développement professionnel, VEIEnjeux, n. 124, mar. 2001.

WAGENSCHEIN, Miriam. Reality shock. 1951. Tese (Mestrado)-Departamento de Sociologia, Universidade de Chicago, 1951. (não publicada).

WARNER, W. Lloyd; LUNT, Paul. The social life of a modern community. New Haven: Yale University Press, 1941.

WINGET, John. Ecological and socio-cultural factors in teacher inter-school mobility. s.d. Tese (Doutorado).

\section{SOBRE O AUTOR}

Howard S. Becker é doutor em sociologia pela Universidade de Chicago. É professor aposentado da Universidade de Washington.

E-mail: hsbecker@earthlink.net 